\title{
Using E-Leadership as a Strategic Tool in Enhancing Organizational Commitment of Virtual Teams in Foreign Commercial Banks in North West Bank -Palestine
}

\author{
Raed A. M. Iriqat ${ }^{1} \&$ Dana M. S. Khalaf ${ }^{2}$ \\ ${ }^{1}$ Business Administration Department, Faculty of Administrative and Financial Sciences, Arab American University, \\ Palestine \\ ${ }^{2}$ Master student, Faculty of Graduate Studies, Arab American University, Palestine \\ Correspondence: Raed Ali Mahmoud Iriqat, Business Administration Department, Faculty of Administrative and \\ Financial Sciences. Arab American University, P. O. BOX 240, Jenin-West Bank, Palestine. Tel: 970-5-9538-6355.
}

Received: September 19, 2017

Accepted: October 11, 2017

Online Published: October 26, 2017

doi:10.5430/ijba.v8n7p25

URL: https://doi.org/10.5430/ijba.v8n7p25

\begin{abstract}
Using information technologies in organizations has been one of the most important topics for numerous scholars in the business field. This manuscript aims to investigate the impact of using E-leadership as a strategic tool in enhancing the organizational commitment of virtual teams in foreign commercial banks in Northern West Bank in Palestine. Primary data was collected via questionnaires which distributed on virtual teams in foreign commercial banks in North West Bank - Palestine. Researchers used a purposive sample which is suitable to study objectives. The empirical model in this study illustrates the relationship among E leadership dimensions (i.e. Envision, engage, energize, empower, execute, and elastic), perceptions of organizational commitment. This manuscript employs simple regression analysis to examine the impact of E-leadership on organizational commitment. In addition, researchers use Pearson correlation matrix to identify the relationship between the six dimensions of E-leadership and organizational commitment.

The result proves that positive impact of using E-leadership as a strategic tool in enhancing the organizational commitment of virtual teams in foreign commercial banks is significant. Also, finds that there is a positive significant relationship between E-leadership and its six dimensions with organizational commitment.
\end{abstract}

Keywords: E- leadership, organizational commitment, virtual teams, foreign commercial banks, North West Bank

\section{Introduction}

Information and communication technology (ICT) change and reform the traditional form of leadership in organizations. Using new technology in an organization produce changing in thinking, leading, workforce performance. Also, it creates new concepts, such as E-environment, E-leader, E- leadership, E- CRM, and virtual teams. E-leadership is a new leadership paradigm with same traditional leadership objectives. E-Leadership achieves same goals of traditional leadership via information technology. Avolio \& Kahai (2003) argue that E-leadership as same as traditional leadership aims to build and enhance the relationship between employees in an organization.

E-leadership is defined as "a dynamic, robust system embedded within a larger organizational system," (Avolio \& Kahai, 2003). One of the most important elements of E- leadership is the virtual teams. Zigurs (2003) shows that leadership in virtual teams communicated through technology, which means e-leaders must know how to use ICT in a meaningful way. Bishop et al., (2010) point out that the misunderstanding between e- leader and his virtual teams is often caused by lack of information.

Globalization, using ICT in an organization and e-environment lead to an increasing interest in studying organizational commitment to understanding the impact of technology on workforce performance, especially, for virtual teams. Organizational commitment (OC) had been developed through 1970's \& 1980's as a significant factor of the relationship among employees and business organizations. (Mowday et al., 1982) According to the several previous studies, leadership styles and organizational commitment are closely correlated. The importance of studying E-leadership has increased in parallel with the growth of using the ICT in the organizations. Moreover, scholars in 
this area of research provide different models to understand the role of E leadership in an organization, which, in turn, provides new challenges and opportunities in business organizations.

The Banking sector in Palestine consist 15 banks with more than 200 branches and offices, 8 of them are foreign (Arab) banks, and 7 are local banks (PMA, 2017). Banking sector faces political and economic barriers in operating business activities. In addition, banks and their branches and offices are depended on ICT to do their overall jobs. It means banks adopt advanced technologies into banking operations, not only in technical issues which aim to develop and to increase the efficiency of operations. However, it also used as a lead instrument to improve the employees' performance. Moreover, Kaufman and Goldstein (2008) argue that financially successful organizations should have leaders who can envision, engage, and execute their teams. Also, Bass (1990) mentions that empowerment is the most appropriate technique to ensure effective leadership in e- teams.

Therefore, banks work in e-business environment, where leaders are e-leaders and teams are virtual teams. Our study based on six characteristics and principles of exceptional leadership (6 Es of E-leadership): Envision, Engage, Energize, Empower, Execute, and Elastic. The study explores if the 6 Es are correlated to the organizational commitment or not. And to investigate the role of using E-leadership in the organizational commitment of virtual teams.

Thus, this study aims to investigate the impact of using E-leadership as a strategic tool in enhancing the organizational commitment of virtual teams in the foreign commercial bank in Northern West Bank. This study divided into six sections: (1) introduction, (2) literature review, (3) hypotheses, (4) methodology, (5) findings, and (6) conclusions.

\section{Literature Review}

Using technologies in organizations has been one of the most important topics for numerous scholars in the business field. Several theoretical and empirical literature discussed the impact of using new technologies and computerizations within the organizations. The results of these articles build up new concepts in business and management, such as E-leadership, ECRM, and E-Government...etc. Information revolution (IR) is rapidly developing, new communication technologies (i.e., internet, emails, faxes, video conferences, Skype, and mobile technology devices) help organizations to enhance their performance. Consequently, IR changes and shape up a new work environment that called E environment. The letter E became public, especially when e-mail word become common as the first word started with. Increasingly, the leadership, the leaders, the teams and other factors reserve their place in E environment.

The concept of leadership is a dynamic concept, Schmid (2008) points out that leadership involves processes of constant change in the leaders themselves, their skills, their followers...etc. Many scientific studies aim to explore the leadership styles impact on the several variables related to the organizational performance and deal with a wide range of areas. (i.e., the concept of leadership, leadership styles (Bass et al., 2003), gender leadership styles (Iriqat, 2017), virtual leadership (Kerfoot, 2010), theories (Avolio et al., 2000), and the relationship between leadership and several variables such as organizational commitment (Asaari et al., 2016).

According to (Cummings et al., 2010) there are four elements involved in the most common definitions of leadership, which are (1) leadership is a process, (2) entails influence, (3) occurs within a context, and (4) includes achieving common goals. Kaufman and Goldstein (2008) mention that leadership aims to create a type of culture where people feel energized and encouraged to do difficult missions the role of Leadership on performance can be classified into approaches (task - oriented and relationship oriented), that emphasize the relationships and work facilitation in organizations to achieve their goals. Bass (1990) shows that relationship- oriented approach ensures a great importance of trust within the teams within the organizations.

Burns (1978) provides transformational and transactional leadership. Both styles are most important examples of relationship-oriented leadership styles, which focus on people and relationship. Bass (1990) shows that transformational leader has better relationships with his followers than a transactional leader in an organization. Moreover, Emery \&Baker (2007) confirm that transformational leaders emphasize the work standards and taskoriented, whereas transformational leaders emphasize on motivating followers.

Judge \& Piccolo (2004), Bass et al., (2003) determine and use four dimensions of transformational leadership which are: (1) idealized influence, (2) inspirational motivation, (3) intellectual stimulation, and (4) individualized consideration, and two dimensions of transactional leadership which are: (1) contingent reward, (2) management by exception (active and passive). 
Virtual teams defined by Anderson et al., (2007) as the team with members located in different locations. Virtual teams working include exchange the information through the Internet, consequently, they use different tools compared with face-to-face teams in doing their tasks and to link people in different venues (i.e., video conferencing, teleconference, instant messaging, etc.). This kind of team creates a new type of leadership, which is considered as E leadership (virtual leadership). Avolio et al., (2000) defined E-leadership "as a social influence process mediated by ATS (advanced information technology) to produce a change in attitudes, feelings, thinking, behavior, and/or performance with individuals, groups, and/or organizations. Similarly, Kerfoot (2010) defined virtual leadership" as leading an organization that is other than physical". Avolio et al., (2000) argue that at any hierarchical level in an organization E-leadership can occur. Kerfoot (2010) shows that the traditional and E-leadership facing same challenges, but for e leadership, challenges occur in different places where no direct interaction and supervision. Therefore, e-leaders needed to develop new skills to cross e-environment barriers. On another hand, Avolio et al., (2000); Roebuck, et al., (2004) mention that unique challenges occurred because there is no trust in the E-leadership since trust is critical for virtual teams. Huang et al., (2009) focus on decision-making challenges, Karpova et al., (2009) identify time difference and lack of nonverbal cues as challenges. Chang and Lee (2013) argue that transactional and transformational leadership styles should use by E- leaders.

On other hands, several previous studies linked trust with organizational commitment, Perry (2004) Shows that trust and organizational commitment are not empirically related to each other. However, the trust in supervisors plays a big role in promoting organizational commitment. Also, Isik and Aliyev (2015) argue that trust increases organizational commitment and impacts on athor variables such as turnover and innovation behavior. Whereas Iriqat (2016) points out that organizational commitment is very important factor in enhancing employee's performance. Mowday et al., (1982) define Organizational commitment as 'the relative strength of an individual's identification with and involvement in a particular organization'. It also shows that leadership is considered as a key of organizational commitment. Porter et al., (1974); Meyer \&Allen (1997); Wasti (2005); and Iriqat (2016) show that there are three types of organizational commitment: affective commitment, continuance commitment, and normative commitment. Additionally, Zangaro (2001) suggests alienative commitment as a fourth type.

Further explaining the relationship between leadership styles and organizational commitment, Yeh \& Hong (2012); Lyndon et al., (2015); Mosadeghrad \& Ferdosi (2013), Dale \& Fox (2008) confirm that leadership and OC are positively correlated, additionally, Bushra et al., (2011) shows that transformational leadership style is positively affected on OC. Whereas Zehir et al., (2012) argue that, there is a positive relationship between leadership style and commitment to the supervisor. Asaari et al., (2016) confirm that transformational style and charisma leadership positively impacted on OC in public universities in Malaysia.

\section{Hypothesis}

First null hypothesis: The E-leadership doesn't play an impacted role in the organizational commitment of virtual teams in foreign commercial banks.

First alternative hypothesis: The E-leadership play an impacted role in the organizational commitment of virtual teams in foreign commercial banks.

Second null hypothesis: The dimensions of E-leadership are not empirically correlated to perception organizational commitment of virtual teams in foreign commercial banks.

Second alternative hypothesis: The dimensions of E-leadership are empirically correlated to perception organizational commitment of virtual teams in foreign commercial banks.

\section{Methodology}

\subsection{Data Collection and Reliability}

Data is collected using questionnaire from virtual teams in foreign commercial banks in Northern West Bank. Our questionnaire consists three parts graded on 5 Likert scale from strongly agree to strongly disagree (5-1). The first part is E-leaders behavior: were measured by 4 items. The second part which is related to E-leadership, this part measured by 47 items distributed in six dimensions (Envision, engage, energize, empower, execute, and elastic). The third part which is related to organizational commitment, this part measured by 15 items which used by (Iriqat, 2016). Based on Cronbach's Alpha equation, the reliability for the first part (E-leader's behavior) was (0.905), the second part (E-leadership) was (0.930), and (0.817) for the third part (organizational commitment). Overall questionnaire achieves (0.915). 


\subsection{Population and Sample}

According to Palestine Monetary Authority (2017), there are 8 foreign Commercial Banks with more than 100 branches in Palestine. Researchers use a purposive sample which is suitable to study objectives.

\subsection{Model Specification}

This study employs simple regression analysis to examine the impact of E-leadership on organizational commitment. In addition, researchers use Pearson correlation matrix to identify the relationship between the six dimensions of E-leadership and organizational commitment. Table 1 represents dependent and independent variables in this study.

Table 1. Study variables and its related indicators

\begin{tabular}{lcl}
\hline Variables & \multicolumn{1}{c}{ Type } & Related indicators \\
\hline E-leadership & Independent & Envision \\
\cline { 3 - 3 } & & Engage \\
& & Energize \\
\cline { 3 - 3 } & & Empower \\
\cline { 3 - 3 } & & Execute \\
\hline Organizational & Elastic \\
\hline
\end{tabular}

Source: own

\section{Research Findings}

\subsection{Descriptive Analysis}

Table 2 represents descriptive statistics of E-leaders behavior, as shown in table below, (E-leader organizes you and tell you what and how to do your job) achieved highest rank with mathematical mean 4.13 and standard deviation 0.860, whereas, (E-leader listens, encourages and facilitates doing your job) achieved lowest rank with mathematical mean 3.93 and standard deviation 0.980. In general, all statements in Table 2 achieved a high degree.

Table 2. Descriptive statistics of E-leader's behavior

\begin{tabular}{lccc}
\hline E-Leader behavior & Mean & $\begin{array}{c}\text { Standard } \\
\text { Deviation }\end{array}$ & Rank \\
\hline E-leader give you freedom to decide the way you do your job & 3.97 & 1.098 & 3 \\
\hline E-leader organizes you and tell you what and how to do your job & 4.13 & 0.860 & 1 \\
\hline E-leader explains, sells and consults you about how is your job going & 4.03 & 0.928 & 2 \\
\hline E-leader listens, encourages and facilitates doing your job & 3.93 & 0.980 & 4 \\
\hline
\end{tabular}

Source: own

Table 3 represents descriptive statistics the variables used in the model. It also shows the means, standard deviations, and the degrees. As shown in Table 2, E-leadership achieved a high degree with mathematical mean 4.2482, and small standard deviation 0.31142 , as well as, organizational commitment also achieved a high degree with mathematical mean 4.1489, and small standard deviation 0. 37208. Otherwise, the six dimensions of E-leadership achieves high degree with mathematical means ranged between 4.2083 and 4.3417. Due to the previous findings, it's obvious that the foreign commercial banks used the concept of E-leadership in high level and the virtual teams in these banks achieve a high degree of organizational commitment. 
Table 3. Descriptive statistics of E-leadership dimensions \& organizational commitment

\begin{tabular}{llcl}
\hline Variables & Mean & Standard Deviation & Degree \\
\hline Envision & 4.2250 & .32563 & High \\
\hline Engage & 4.2333 & .51899 & High \\
\hline Energize & 4.3000 & .33160 & High \\
\hline Empower & 4.2083 & .34792 & High \\
\hline Execute & 4.3417 & .32486 & High \\
\hline Elastic & 4.2048 & .45746 & High \\
\hline E leadership & $\mathbf{4 . 2 4 8 2}$ & $\mathbf{. 3 1 1 4 2}$ & High \\
\hline Organizational commitment & $\mathbf{4 . 1 4 8 9}$ & $\mathbf{. 3 7 2 0 8}$ & High \\
\hline
\end{tabular}

Source: own research analysis

First null hypothesis: The E-leadership doesn't play an impacted role in the organizational commitment of virtual teams in foreign commercial banks.

First alternative hypothesis: The E-leadership play an impacted role in the organizational commitment of virtual teams in foreign commercial banks.

Table 4 presents that the overall model is significant ( $p$-value $=0.000$ ). As shown in the table below, the value of $R$ square and R square adjusted is 0.381 and 0.359 respectively, thus, the empirical model has successfully explained the impact of $\mathrm{E}$ leadership on organizational commitment of virtual teams in foreign commercial banks.

Table 4. Model summary and ANOVA for empirical model

\begin{tabular}{|c|c|c|c|c|c|c|c|}
\hline Model & $\begin{array}{c}\text { Sum of } \\
\text { Squares }\end{array}$ & $\begin{array}{l}\text { Mean } \\
\text { Square }\end{array}$ & $\mathbf{F}$ & Sig. & $\mathbf{R}$ & $\begin{array}{c}\text { R } \\
\text { Square }\end{array}$ & $\begin{array}{l}\text { Adjusted R } \\
\text { Square }\end{array}$ \\
\hline Regression & 1.530 & 1.530 & \multirow{3}{*}{17.236} & \multirow{3}{*}{$.000^{\mathrm{a}}$} & \multirow{3}{*}{$.617^{\mathrm{a}}$} & \multirow{3}{*}{.381} & \multirow{3}{*}{.359} \\
\hline Residual & 2.485 & \multirow{2}{*}{.089} & & & & & \\
\hline Total & 4.015 & & & & & & \\
\hline
\end{tabular}

\section{a. Predictors: (Constant), E-Leadership}

b. Source: own

Table 5 presents the result of the estimated empirical model. The impact of E-leadership on organizational commitment of virtual teams in foreign commercial banks is empirically confirmed. Likewise, the equation below is proved that positive impact of E-leadership on organizational commitment of virtual teams in foreign commercial banks is significant with P-value equal 0.00 .

Table 5. The OLS Summary statistics of the first null hypothesis

\begin{tabular}{|c|c|c|c|c|c|}
\hline \multirow[t]{2}{*}{ Model (Variables) } & \multicolumn{2}{|c|}{ Unstandardized coefficients } & \multirow{2}{*}{$\begin{array}{r}\begin{array}{c}\text { Standardized } \\
\text { coefficients }\end{array} \\
\text { Beta }\end{array}$} & \multirow[t]{2}{*}{ T- value } & \multirow[t]{2}{*}{ P-value } \\
\hline & $\mathbf{B}$ & Std. Error & & & \\
\hline (Constant) & 1.016 & .757 & & 1.342 & .190 \\
\hline E- leadership & .738 & .178 & .617 & 4.152 & .000 \\
\hline
\end{tabular}

Source: own 


\section{Organizational Commitment $=1.016+.738 \mathrm{E}-$ Leadership}

Second null hypothesis: The dimensions of E-leadership are not empirically correlated to perception organizational commitment of virtual teams in foreign commercial banks.

Second alternative hypothesis: The dimensions of E-leadership are empirically correlated to perception organizational commitment of virtual teams in foreign commercial banks.

Pearson correlation matrix among 6 E-leadership dimensions, total value of E- leadership, and organizational commitment of virtual teams is presented in Table 6. The results show that there is a significant positive relationship between organizational commitment and each of envision, engage, energize, empower, execute, and elastic where ( $\mathrm{r}$ $=.397, \mathrm{p}<0.05),(\mathrm{r}=.494, \mathrm{p}<0.01),(\mathrm{r}=.638, \mathrm{p}<0.01),(\mathrm{r}=.588, \mathrm{p}<0.01),(\mathrm{r}=.499, \mathrm{p}<0.01)$, and $(\mathrm{r}=.449, \mathrm{p}<$ $0.05)$ respectively. Whereas, the total value of E leadership is positively correlated to organizational commitment of virtual teams where $(r=-.617, \mathrm{p}<0.01)$. In addition, there is a strong positive relationship between E- leadership and each single dimension in this study, which are envision, engage, energize, empower, execute, and elastic, where $(\mathrm{r}=0.715, \mathrm{p}<0.01),(\mathrm{r}=.798, \mathrm{p}<0.01),(\mathrm{r}=.816, \mathrm{p}<0.01),(\mathrm{r}=.945, \mathrm{p}<0.01),(\mathrm{r}=.755, \mathrm{p}<0.01)$, and $(\mathrm{r}=.861, \mathrm{p}<$ $0.05)$ respectively. Moreover, table 6 shows all six dimensions of E leadership are empirically correlated to each other. Thus, we accepted the second alternative hypothesis, that the dimensions of E-leadership are empirically correlated to perception organizational commitment of virtual teams in foreign commercial banks.

Table 6. Pearson correlation matrix between dimensions of E-leadership \&organizational commitment

\begin{tabular}{|c|c|c|c|c|c|c|c|c|}
\hline Variables & 1 & 2 & 3 & 4 & 5 & 6 & 7 & 8 \\
\hline Envision & 1 & $.457^{*}$ & $.538^{* * *}$ & $.640 * *$ & $.420^{*}$ & $.503^{* * *}$ & $.715^{* *}$ & $.397^{*}$ \\
\hline Engage & $.457^{*}$ & 1 & $.609^{* * *}$ & $.695 * *$ & $.393^{*}$ & $.701^{* * *}$ & $.798^{* *}$ & $.494^{* * *}$ \\
\hline Energize & $.538^{* * *}$ & $.609^{* *}$ & 1 & $.731^{* * *}$ & $.623^{* * *}$ & $.620^{* * *}$ & $.816^{* * *}$ & $.638^{* * *}$ \\
\hline Empower & & & & 1 & $.737^{* *}$ & $.765^{* *}$ & $.945^{* *}$ & $.588^{* *}$ \\
\hline Elastic & & & & & 1 & $.570^{* *}$ & $.755^{* *}$ & $.499^{* * *}$ \\
\hline Elastic & & & & & & 1 & $.861^{* * *}$ & $.449^{*}$ \\
\hline E-leadership & & & & & & & 1 & $.617^{* *}$ \\
\hline Organizational commitment & & & & & & & & 1 \\
\hline
\end{tabular}

*: confidence level at $0.05, * *$ : confidence level at 0.01 .

Source: own research analysis

\section{Conclusion}

Using new technology in an organization produces changing in thinking, leading and workforce performance. Also creates new concepts, such as E- leadership and virtual teams. E-leadership is considered to be a social influence process that is mediated by technology. E-leadership is designed to produce changes in performance, thinking, feelings, and behavior for recipients to provide guidance in getting a corporate goal. This study aims to investigate the impact of E-leadership on organizational commitment of virtual teams in foreign commercial banks in Northern West Bank. Foreign commercial banks and their branches and offices depended on ICT to do their overall jobs and achieving their objectives. Therefore, banks tend to work within e-business environment. Thus, the relationships between $\mathrm{t}$ E-leadership and organizational commitment of the virtual teams in relation to the banking industry are important to understanding.

Mainly, the results prove that (1) the foreign commercial banks used the concept of E-leadership in high level and the virtual teams in these banks achieve a high degree of organizational commitment. (2) A Positive impact of E-leadership on organizational commitment of virtual teams in foreign commercial banks is significant. (3) There is a positive significant relationship between E-leadership and its six dimensions with organizational commitment. 


\section{References}

Anderson, A. H., McEwan, R., Bal, J., \& Carletta, J. (2007). Virtual team meetings: An analysis of communication and context. Computers in Human Behavior, 23(5), 2558-2580. https://doi.org/10.1016/j.chb.2007.01.001

Asaari, M. H. A. H., Dwivedi, A., Lawton, A., \& Desa, N. M. (2016). Academic Leadership and Organizational Commitment In Public Universities of Malaysia. European Scientific Journal, 12(16). https://doi.org/10.19044/esj.2016.v12n16p329

Avolio, B. J., \& Kahai, S. S. (2003). Adding the "E" to E-leadership: How it may impact your leadership. Organizational Dynamics, 31(4), 325-338. https://doi.org/10.1016/S0090-2616(02)00133-X

Avolio, J. B., Kahai, S., \& Dodge, G. E. (2000). E-leadership Implications for theory, research, and practice. The Leadership Quarterly, 11(4), 615-668. https://doi.org/10.1016/S1048-9843(00)00062-X

Bass, B. M. (1990). Bass \& Stogdill's Handbook of Leadership: Theory, Research, and Managerial Applications (3rd ed.). USA: The Free Press.

Bass, B. M., Avolio, B. J., Jung, D. I., \& Berson, Y. (2003). Predicting unit performance by assessing transformational and transactional leadership. Journal of applied psychology, 88(2), 207. https://doi.org/10.1037/0021-9010.88.2.207

Bishop, A., Riopelle, K., Gluesing, J., Danowski, J., \& Eaton, T. (2010). Managing global compliance through collaborative innovation networks. Procedia-Social and Behavioral Sciences, 2(4), 6466-6474. https://doi.org/10.1016/j.sbspro.2010.04.056

Burns, J.M. (1978). Leadership. New York: Harper and Row.

Bushra, F., Ahmad, U., \& Naveed, A. (2011). Effect of transformational leadership on employees' job satisfaction and organizational commitment in banking sector of Lahore (Pakistan). International journal of Business and Social science, 2(18).

Chang, W. L., \& Lee, C. Y. (2013). Virtual team e - leadership: The effects of leadership style and conflict management mode on the online learning performance of students in a business - planning course. British Journal of Educational Technology, 44(6), 986-999. https://doi.org/10.1111/bjet.12037

Cummings, G. G., MacGregor, T., Davey, M., Lee, H., Wong, C. A., Lo, E., \& Stafford, E. (2010). Leadership styles and outcome patterns for the nursing workforce and work environment: a systematic review. International Journal of Nursing Studies, 47(3), 363-385. https://doi.org/10.1016/j.ijnurstu.2009.08.006

Dale, J., \& Fox, M. (2008). Leadership style and organizational commitment: Mediating effect of role stress. Journal of Managerial Issues, 20(1), 109-130.

Emery, C. R., \& Barker, K. J. (2007). The effect of transactional and transformational leadership styles on the organizational commitment and job satisfaction of customer contact personnel. Journal of Organizational Culture, Communications and Conflict, 11(1), 77.

Huang, H. C. (2009). Designing a knowledge-based system for strategic planning: A balanced scorecard perspective. Expert Systems with Applications, 36(1), 209-218. https://doi.org/10.1016/j.eswa.2007.09.046

Iriqat, R. A. (2016). Organizational Commitment Role in Mediating the Impact of the Organizational Culture Dimensions on Job Satisfaction for MFIs' Employees in Palestine. International Journal of Business and Social Science, 7(5), 125-135.

Iriqat, R. A. M. (2017). Gender Leadership Styles in Enhancing Workforce Performance in Palestinian Public Institutions: The Role of Mediating Organizational Citizenship Behavior. International Review of Management and Business Research, 6(1), 93.

Isik, M., \& Aliyev, Y. (2015). The Relationship between Teamwork and Organizational Trust. International Journal of Research in Business and Social Science, 4(1), 133.

Judge, T. A., \& Piccolo, R. F. (2004). Transformational and transactional leadership: a meta-analytic test of their relative validity. Journal of applied psychology, 89(5), 755. https://doi.org/10.1037/0021-9010.89.5.755

Karpova, E., Correia, A. P., \& Baran, E. (2009). Learn to use and use to learn: Technology in virtual collaboration experience. The Internet and Higher Education, 12(1), 45-52. https://doi.org/10.1016/j.iheduc.2008.10.006 
Kaufman, K., \& Goldstein, L. (2008). Leadership and successful financial performance in healthcare. Bulletin of the National Center for Healthcare Leadership, 8-22.

Kerfoot, K. M. (2010). Listening to see: The key to virtual leadership. Nursing Economics, 28(2), 114-115.

Lyndon, A., Johnson, M. C., Bingham, D., Napolitano, P. G., Joseph, G., Maxfield, D. G., \& O'keeffe, D. F. (2015). Transforming communication and safety culture in intrapartum care: A multi - organization blueprint. Journal of Obstetric, Gynecologic, \& Neonatal Nursing, 44(3), 341-349. https://doi.org/10.1111/1552-6909.12575

Meyer, J., \& Allen, N. J. (1997). Commitment in the workplace: Theory, research and application. Thousand Oaks, CA: Sage.

Mosadeghrad, A. M., \& Ferdosi, M. (2013). Leadership, job satisfaction and organizational commitment in healthcare sector. Proposing and testing a model. Materia socio-medica, 25(2), 121. https://doi.org/10.5455/msm.2013.25.121-126

Mowday, R. T., Porter, L. W., \& Steers, R. M. (1982). Employee-organization linkages. New York: Academic Press.

Perry, R. W. (2004). The relationship of affective organizational commitment with supervisory trust. Review of Public Personnel Administration, 24(2), 133-149. https://doi.org/10.1177/0734371X03262452

Porter, L. W, Steers, R. M., Mowday, R. T, \& Boulian, P. V (1974). Organizational commitment, job satisfaction, and turnover among psychiatric technicians. Journalof Applied Psychology. 59, 603-609. https://doi.org/10.1037/h0037335

Roebuck, D. B., Brock, S. J., \& Douglas R. (2004). Using a Simulation to Explore the Challenges of Communicating. Business Communication Quarterly, 67, 359. https://doi.org/10.1177/1080569904268083

Schmid, H. (2008). Leadership styles and leadership change in human and community service organizations. In Handbook of community movements and local organizations (pp. 395-409). Springer US. https://doi.org/10.1007/978-0-387-32933-8_26

Wasti, S. A. (2005). Commitment profiles: Combinations of organizational commitment forms and job outcomes. Journal of Vocational Behavior, 67(2), 290-308. https://doi.org/10.1016/j.jvb.2004.07.002

Yeh, H., \& Hong, D. (2012). The mediating effect of organizational commitment on leadership type and job performance. The Journal of Human Resource and Adult Learning, 8(2), 50.

Zangaro, G. (2001). Organizational commitment: A concept analysis. Nursing Forum, 36(2), 14-22. https://doi.org/10.1111/j.1744-6198.2001.tb01179.x

Zehir, C., Sehitoglu, Y., \& Erdogan, E. (2012). The Effect of Leadership and Supervisory Commitment to Organizational Performance. Procedia - Social and Behavioral Sciences, 58, 207-216. https://doi.org/10.1016/j.sbspro.2012.09.994

Zigurs, I., (2003). Leadership in virtual teams: Oxymoron or opportunity? Organization Dynamics, 31, 339-351. https://doi.org/10.1016/S0090-2616(02)00132-8 